\title{
Pica; A psychiatric syndrome with surgical consequences
}

\author{
Loudjedi $S^{1}$, Bereksi $A^{1}$, Toaba $T^{1}$, Boughezzal $F^{1}$, Kherbouche $M^{1}$, Bensenane $M^{2}$ and Dib $F^{3}$ \\ ${ }^{1}$ Department of Surgery B, CHU Tlemcen, University of Tlemcen, Algeria \\ ${ }^{2}$ Department of Anesthesiology reanimation, CHU Tlemcen, University of Tlemcen, Algeria \\ ${ }^{3}$ Department of Gastro-enterology, University of Tlemcen, Algeria
}

\section{Introduction}

Pica is an eating disorder typically defined as the persistent eating or mouthing of non-nutritive substances. The condition's name comes from the Latin word for magpie, a bird that is reputed to eat almost anything [1-4]. Pica is seen in all ages, infants, children, elders, those with developmental disabilities (autism or mentally retarded) and in pregnant women. The true incidence of pica is not known but it is estimated to be $75 \%$ in infants, $15 \%$ in two-three year old toddlers and $10-33 \%$ among the institutionalized mentally retarded children $[5,6]$. This paper reports the management of a 18 year old patient with PICA disorder.

The condition has been described in medical journals for centuries [7-9]. One of the first cases of pica was noted in 6th century AD and was observed in a pregnant woman [7]. Since then, many cases of pica have been reported where patients have acknowledged ingesting ice cubes (pago-phagia), clay (geophagia), dried pasta (amylophagia), chalk, starch, paste, Kayexalate resin (resinphagia), tomatoes, lemons, cigarette butts, hair, lead, and laun-dry starch (for example, Argo out of the box) [7-13]. Although pica is most prominent in individuals with developmental disabilities, it has been observed in men and women of all ages and ethnicity, but is more prevalent among the lower socioeconomic classes $[9,10]$.

Worldwide, $25 \%$ to $33 \%$ of all pica cases involvesmall children, $20 \%$ are pregnant women, and $10 \%$ to $15 \%$ are individuals with learning disabilities [14]. A small percentage of patients have iron deficiency anemia. Pica poses significant health risks that often require medical interventions. These patients are susceptible to electrolyte and metabolic disorders, lead and mercury poisoning, hypokalemia (from resinphagia), parasitic infections, tooth wear, intestinal obstruction, and various problems of the gastrointestinal tract $[9,12-15]$.

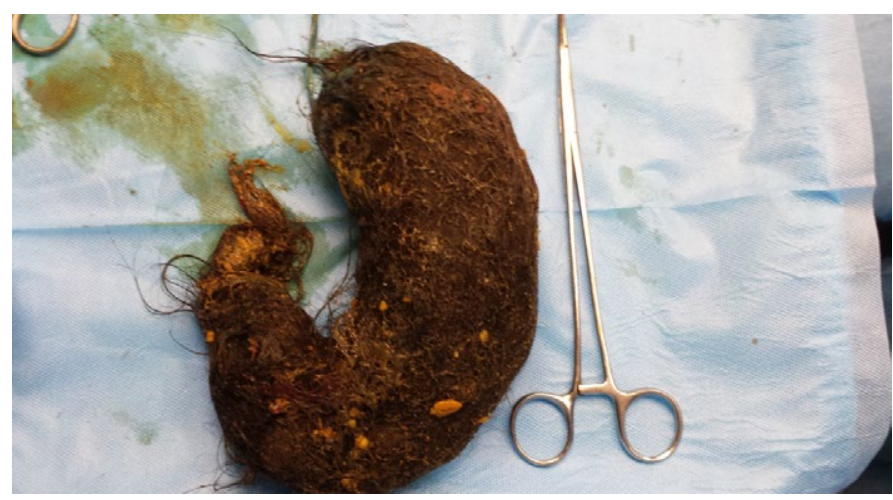

Figure 1. Giant gastric Trichobezoar.

\section{Observation}

A 17-year-old girl, developing and growing appropriately for age, was brought to emergency by her father with the chief complaint: abdominal pain. On general physical examination the patient was mild anemic with pallor, well oriented, conscious on oral examination with generalized blanched mucosa. Examination of the abdomen found a generalized contracture and an abdominal mass. The white blood cell count 18,000 .

Ultrasound and CT scan revealed the presence of a foreign body in the stomach and the small bowel. The patient was admitted to the operating room. At the opening of the abdomen, the stomach is very

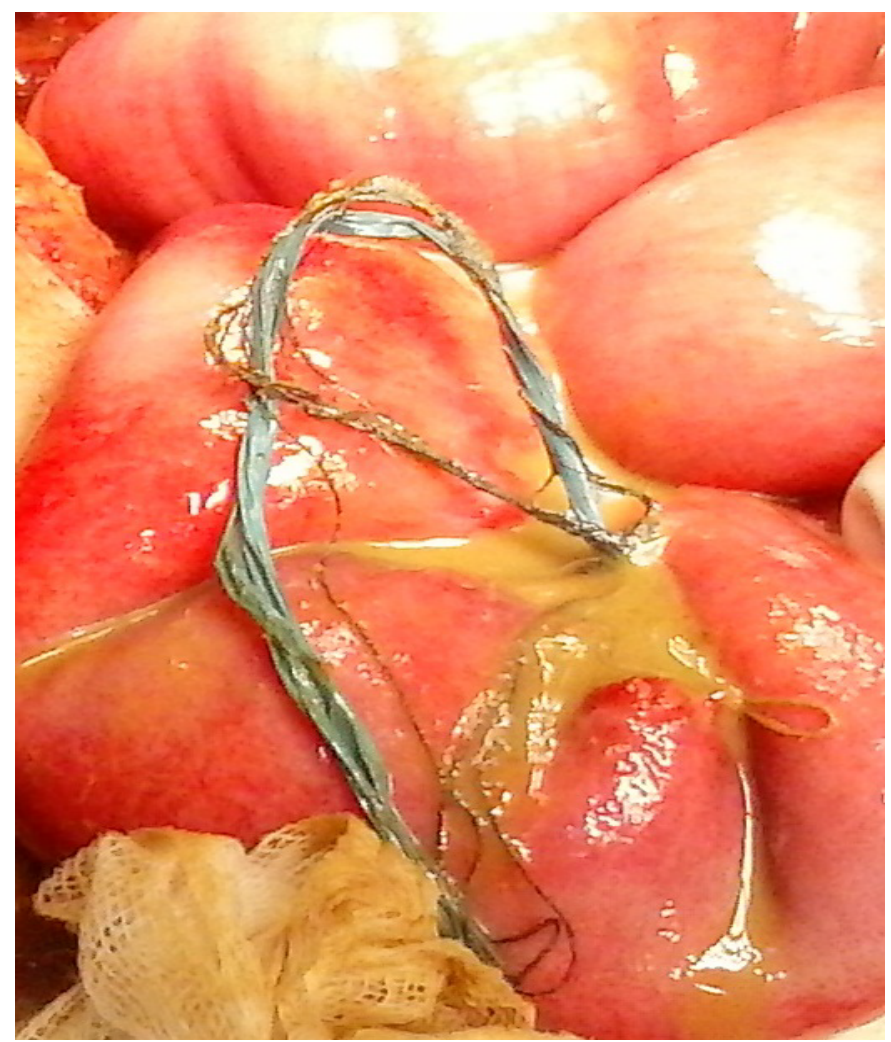

Figure 2. Electric wire perforated the small bowel.

Correspondence to: Loudjedi S, Department of Surgery B, CHU Tlemcen, University of Tlemcen, Algeria, Tel: 043-21-18-06; E-mail: loudjedi_salim13@yahoo.fr

Received: May 10, 2015; Accepted: June 22, 2015; Published: June 26, 2015 
hard like a cancer. We practice a gastrostomy; is removed a huge Trichobezoar simulating the stomach anatomy (Figures 1 and 2).

Discovery of an electric wire which perforated small bowel. This thread extends over the whole length of the intestine and even the colon and the rectum where it is palpable. Extraction of the foreign body is done by enterotomy. The patient died a few hours after the procedure due to septic shock. On further explicit questioning about particular eating habits, the patient reluctantly disclosed an almost daily consumption of hair and other substances not specified by her family.

\section{References}

1. Stedman's medical dictionary 28th edition, p1495.

2. Emedince.com article on "Eating Disorder: Pica"

3. Thyer BA, Wodarski JS (2007) Social work in mental health: an evidence-based approach. John Wiley and Sons 33.

4. Joginder Singh Gulia, The Internet Journal Of Head And Neck Surgery.

5. Boris NW, Dalton R (2004) Pica. In: Behrman RE, Klegman RM, Jenson HB (Eds.), Nelson textbook of pediatrics. (17thedn), New Delhi, Elsevier.
6. Chatoor I (2005) Feeding and eating disorders of infancy and early childhood. In: Kaplan and Sadocks Comprehensive textbook of Psychiatry. (8thedn), Philidelphia, Lippincot Williams and wilkins 3217-3227.

7. Coltman CA Jr (1969) Pagophagia and iron lack. JAMA 207: 513-516. [Crossref]

8. Kushner RF, Gleason B, Shanta-Retelny V (2004) Reemergence of pica following gastric bypass surgery for obesity: a new presentation of an old problem. J Am Diet Assoc 104: 1393-1397. [Crossref]

9. Grotegut CA, Dandolu V, Katari S, Whiteman VE, Geifman-Holtzman O, et al. (2006) Baking soda pica: a case of hypokalemic metabolic alkalosis and rhabdomyolysis in pregnancy. Obstet Gynecol 107: 484-486. [Crossref]

10. Grivetti LE (1978) Culture, diet and nutrition: selected themes and topics. Bio Science 28: 171-177.

11. Hackworth SR, Williams LL (2003) Pica for foam rubber in patients with sickle cell disease. South Med J 96: 81-83. [Crossref]

12. Kathula SK (2008) Craving lemons: another form of pica in iron deficiency. Am J Med 121: e1. [Crossref]

13. Tisman G (1970) "Resinphagia”. N Engl J Med 283: 602. [Crossref]

14. Barker D (2005) Tooth wear as a result of pica. Br Dent $J$ 199: 271-273. [Crossref]

15. Karnath BM (2004) Anemia in the adult patient. Hospital Physician: 32-36.

Copyright: $\mathbb{C} 2015$ Loudjedi S. This is an open-access article distributed under the terms of the Creative Commons Attribution License, which permits unrestricted use, distribution, and reproduction in any medium, provided the original author and source are credited. 